\title{
Long-Term Metformin Effect on Endometrial Cancer Development Depending on Glucose Environment In Vitro
}

\author{
Amanda Machado Weber, Carsten Lange*, Julia Jauckus, Thomas Strowitzki, Ariane Germeyer \\ Department of Gynecological Endocrinology and Fertility Disorders, Women's Hospital, Ruprecht-Karls University of \\ Heidelberg, Heidelberg, Germany \\ Email: *carsten.lange@med.uni-heidelberg.de
}

How to cite this paper: Weber, A.M., Lange, C., Jauckus, J., Strowitzki, T. and Germeyer, A. (2021) Long-Term Metformin Effect on Endometrial Cancer Development Depending on Glucose Environment In Vitro. Open Journal of Obstetrics and Gynecology, 11, 1172-1189.

https://doi.org/10.4236/ojog.2021.119111

Received: August 10, 2021

Accepted: September 13, 2021

Published: September 16, 2021

Copyright $\odot 2021$ by author(s) and Scientific Research Publishing Inc. This work is licensed under the Creative Commons Attribution International License (CC BY 4.0).

http://creativecommons.org/licenses/by/4.0/

\begin{abstract}
Objectives: Hyperinsulinemia as well as prolonged and elevated estrogen exposure are considered as risk factors for endometrial cancer (EC) development. Metformin, an anti-hyperglycemic and insulin-sensitizing biguanide, displayed anti-proliferative effects in recent studies. In the present study, the effects of long-term exposure of endometrial cancer cells to low and moderate concentrations of metformin on cell viability, proliferation, clonogenicity and migration were investigated under different metabolic conditions. Study Design: EC cell lines HEC-1A and Ishikawa were cultured under normo- (NG, $5.5 \mathrm{mM}$ ) or hyperglycemic (HG, $17.0 \mathrm{mM}$ ) conditions and treated with metformin $(0.01-5.0 \mathrm{mM})$ in the presence of $\beta$-estradiol (E2) for $7 \mathrm{~d}$. Results: A concentration-dependent decrease of cellular viability was observed in the MTT and ATP assays after metformin treatment. $\mathrm{IC}_{50}$ values were between $0.7-3.7 \mathrm{mM}(\mathrm{NG})$ and $3.0-18.3 \mathrm{mM}$ (HG), respectively. A protective effect of glucose on cellular viability was detected only in the ATP assay. Furthermore, metformin $(0.5-5.0 \mathrm{mM})$ led to a significant decrease in proliferation by $12 \%-55 \%(\mathrm{NG})$. However, a decreased proliferation rate was only induced at $5.0 \mathrm{mM}$ metformin (40\%) in the presence of high glucose levels in HEC-1A cells, indicating a glucose-related resistance to anti-proliferative metformin effects, which-to a lesser extent-was also observed in Ishikawa cells. Metformin treatment also caused concentration-dependent effects on clonogenicity and decreased the number and size of colonies. In HEC-1A cells, metformin $(0.5-5.0 \mathrm{mM})$ reduced the colony formation by $44 \%-80 \%$ (NG) and 29\% - 81\% (HG), respectively. Slightly higher metformin concentrations $(1.0-5.0 \mathrm{mM})$ were necessary in Ishikawa cells to reduce clonogenicity by $36 \%-86 \%$ independent of glucose levels. An investigation of migration in the wound healing assay revealed that the $\%$ wound closure decreased
\end{abstract}


with increasing metformin concentrations, but independent of glucose levels. After treatment with $5.0 \mathrm{mM}$ metformin, migration was significantly reduced in both cell lines. Conclusion: Our in vitro findings support the hypothesis that metformin has a direct effect on endometrial cancer cell lines and reflects the importance of the local glucose environment, suggesting that metformin may be considered as a potential adjuvant agent in endometrial cancer therapy due to its direct and indirect effects on endometrial development. However, further studies are necessary that confirm the relevance of our data for clinical applications.

\section{Keywords}

Metformin, Endometrial Cancer, Proliferation, Migration, Clonogenicity

\section{Introduction}

Endometrial cancer (EC) is one of the leading gynecological malignancies [1] and can be classified into an estrogen-dependent type I, accounting for 75\% $85 \%$ of all cases, and an estrogen-independent, more aggressive and invasive type II cancer [2] [3].

One known risk factor for EC development is unopposed estrogen, as seen e.g. during perimenopausal years in women [4]. Estrogen stimulates endometrial cell proliferation and inhibits apoptosis induction in the tissue [5] [6]. Additionally, hyperglycemia contributes to the growth and progression of EC in women with type II diabetes [7], who therefore have an increased risk for EC development [8] and also display a higher cancer mortality rate compared to normoglycemic individuals [9].

Metformin, an anti-hyperglycemic and insulin-sensitizing agent, commonly used in the treatment of type II diabetes, has recently been suggested as a therapeutic agent to inhibit cellular overgrowth and hyperplasia in several tissues, including EC [10] [11]. Previous studies indicated that metformin could be effective as an adjuvant in cancer therapy along with its traditional role in the treatment of type II diabetes [12]-[17]. However, most experimental studies analyzed metformin effects at unphysiologically high concentrations (up to $100 \mathrm{mM}$ ) during short-term treatment of $24-72 \mathrm{~h}$ [18] [19]. We therefore believe that those effects described in the literature are related to cytotoxicity rather than the desired anti-cancer effects of metformin [11]. Considering that the beneficial impact of metformin in EC remains to be determined, this study investigated the direct effects of low and moderate metformin concentrations $(0.01-5.0 \mathrm{mM})$ during long-term treatment ( $7 \mathrm{~d}$ ) on EC cell growth, viability, clonogenicity and motility. As increased estrogen levels are considered as an additional risk factor, $\beta$-estradiol (E2) was added during experiments, a factor that was often omitted in prior studies [18] [19]. Furthermore, cells were exposed to metformin in an environment with normal (5.5 mM, equivalent to $100 \mathrm{mg} / \mathrm{dL})$ or high $(17.0 \mathrm{mM}$, 
equivalent to $306 \mathrm{mg} / \mathrm{dL}$ ) glucose levels in order to mimic a diabetic condition, and thus investigate the metformin effect in different metabolic settings. In a previous study, our group observed an attenuation of metformin-induced anti-proliferative effects in the presence of elevated glucose levels in EC cells with low metformin concentrations $(0.1 \mathrm{mM})$ over a treatment period of $20 \mathrm{~d}$ [20]. In another study by our group, higher metformin concentrations (above $1.0 \mathrm{mM}$ ) led to anti-proliferative effects after a shorter incubation time of $72 \mathrm{~h}$ in EC cells, but not in non-malignant, primary uterine endometrial epithelial cells (eEP). Additionally, a reversal of insulin-induced migration was observed in a high glucose environment [21].

The underlying aim of the current study was to investigate the direct effects of long-term exposure of EC cells to low and moderate concentrations of metformin on cell viability, proliferation, clonogenicity and migration under different metabolic conditions.

\section{Materials and Methods}

\subsection{Cell Culture}

The human endometrial adenocarcinoma cell lines HEC-1A (type II EC, postmenopausal model; HTB112, ATCC, Manassas, VA, USA) and Ishikawa (type I EC, pre-menopausal model; 99040201, Sigma-Aldrich, Munich, Germany) were used for the in vitro experiments. Cells were grown in Eagle's minimal essential medium (MEM; Sigma-Aldrich) supplemented with 5.0 (Ishikawa) or 10\% (v/v) (HEC-1A) charcoal-stripped fetal bovine serum (hormone-reduced FBS; Gibco, Waltham, MA, USA), 1.0\% (v/v) penicillin/streptomycin (Gibco) and $1.0 \%$ $(\mathrm{v} / \mathrm{v})$ non-essential amino acids (Sigma-Aldrich). All cells were grown in an incubator at $37^{\circ} \mathrm{C}$ and $5.0 \% \mathrm{CO}_{2}$ in a humidified environment.

During experiments, cells were maintained in a normoglycemic (NG) environment (5.5 mM glucose), representing physiological blood glucose levels of $100 \mathrm{mg} / \mathrm{dL}$. For the experiments under hyperglycemic (HG) conditions, the medium was supplemented with glucose (Sigma-Aldrich) to achieve a final concentration of $17.0 \mathrm{mM}$ glucose, equivalent to $306 \mathrm{mg} / \mathrm{dL}$ as seen in diabetic patients. A $100 \mathrm{mM}$ stock solution of metformin (Sigma-Aldrich) in deionized water was freshly prepared on the day of administration and further diluted in normo- or hyperglycemic culture medium, respectively, in order to adjust the desired concentrations of the drug $(0.01-5.0 \mathrm{mM})$ during experiments. Furthermore, cell culture media were supplemented with $10 \mathrm{nM}$ E2 (Sigma-Aldrich) during treatments in order to mimic elevated estrogen levels. A $10 \mu \mathrm{M}$ stock solution of E2 was prepared in ethanol (stored at $-20^{\circ} \mathrm{C}$ ) and diluted $(1: 1000)$ in medium directly before the use in experiments (final concentration of ethanol: $0.1 \%(\mathrm{v} / \mathrm{v})$ ). Elevated estrogen levels represent a common risk factor for EC development and progression and are therefore essential for a realistic in vitro simulation of the environment in EC patients and women with increased risk for EC development [4] [5] [22]. 


\subsection{MTT and ATP Cell Viability Assays}

In order to evaluate the effects of metformin on cellular viability, HEC-1A and Ishikawa cells were seeded into transparent (MTT) or opaque-walled, white (ATP) 96-well plates at a density of 5000 cells/well and incubated in a normal or high glucose, drug-free medium for $24 \mathrm{~h}$. Afterwards, cells were treated with different concentrations of metformin $(0.01-20 \mathrm{mM})$ for $7 \mathrm{~d}$ and the medium was changed every 2 - 3 d. Untreated cells (medium (NG or HG) supplemented with $10 \mathrm{nM}$ E2) served as the reference control. For the MTT assay, $20 \mu \mathrm{L}$ of a 2.5 $\mathrm{mg} / \mathrm{mL}$ MTT solution (3-(4,5-dimethylthiazol-2-yl)-2,5-diphenyltetrazolium bromide; Alfa Aesar, Karlsruhe, Germany) was added per well after treatment and incubated at $37^{\circ} \mathrm{C}$ for $4 \mathrm{~h}$. Afterwards, the MTT-containing media was substituted by $50 \mu \mathrm{L}$ DMSO (Carl Roth, Karlsruhe, Germany) for the extraction of insoluble formazan crystals. The absorbance was measured at $\lambda=570 \mathrm{~nm}\left(\mathrm{OD}_{570}\right)$ with a microplate reader (Anthos Microsystems, Friesoythe, Germany) and cellular viability was calculated with the following Equation (1) (cells with DMSO served as a blank sample):

$$
\% \text { cell viability }=\frac{\mathrm{OD}_{570, \text { treatment }}-\mathrm{OD}_{570, \text { blank }}}{\mathrm{OD}_{570, \text { control }}-\mathrm{OD}_{570, \text { blank }}} \times 100 .
$$

For the adenosine triphosphate (ATP) assay, the CellTiter-Glo luminescent assay kit (Promega, Fitchburg, WI, USA) was used. Briefly, $100 \mu \mathrm{L}$ of the CellTiter-Glo reagent solution was added to each well after treatment and mixed on a microplate shaker for $2 \mathrm{~min}$ in order to lyse the cells. Afterwards, the mixture was incubated at room temperature for another $10 \mathrm{~min}$ without shaking and luminescence (integration time: $1 \mathrm{~s}$ ) was detected with a microplate luminometer (Berthold Technologies, Bad Wildbad, Germany). Cellular viability was calculated with the following Equation (2) (medium without cells served as a blank sample):

$$
\% \text { cell viability }=\frac{\text { Luminescence }_{\text {treatment }}-\text { Luminescence }_{\text {blank }}}{\text { Luminescence }_{\text {control }}-\text { Luminescence }_{\text {blank }}} \times 100 .
$$

For both assays, SPSS version 24 (IBM, Armonk, NY, USA) was used for the establishment of concentration-response curves and the calculation of $\mathrm{IC}_{50}$ and $\mathrm{IC}_{90}$ values (inhibitory concentrations, where $50 \%$ and $90 \%$ of the measured effect, i.e. loss of cellular viability, was observed; values were set at the inflection points $\left(\mathrm{IC}_{50}\right)$ of the sigmoidal $\log$ (concentration)-T/C (treated over control) curves). All experiments were carried out in triplicates and repeated at least three times.

\subsection{Cell Proliferation Assay by Crystal Violet Staining}

HEC-1A and Ishikawa cells were seeded into 24-well plates at a density of 5000 cells/well and incubated in a normal or high glucose, drug-free medium for $24 \mathrm{~h}$. Afterwards, cells were treated with different concentrations of metformin (0.01 $5.0 \mathrm{mM}$ ) for $7 \mathrm{~d}$ with renewed treatments by medium changes every $2-3 \mathrm{~d}$. Un- 
treated cells served as the reference control. The relative cell proliferation was measured by crystal violet (CV) staining according to an adapted protocol [23]. Briefly, cells were rinsed twice with phosphate-buffered saline (PBS; Sigma-Aldrich) and stained with $0.5 \%(\mathrm{w} / \mathrm{v}) \mathrm{CV}$ (Carl Roth) in a mixture of $80 \%(\mathrm{v} / \mathrm{v})$ deionized water and $20 \%(\mathrm{v} / \mathrm{v})$ methanol (Carl Roth) for $20 \mathrm{~min}$. After repeated washing with PBS, the CV stain was extracted by incubation with $33 \%(\mathrm{v} / \mathrm{v})$ acetic acid (Carl Roth) in deionized water for $20 \mathrm{~min}$. From each well, $100 \mu \mathrm{L}$ of the extract were transferred into 96-well plates in duplicates and the absorbance was measured at $\lambda=570 \mathrm{~nm}\left(\mathrm{OD}_{570}\right)$ with a microplate reader (Anthos Microsystems). The absorbance of the untreated control group was set to $100 \%$ and the effect of different treatments was compared to the control. Each experiment was performed in duplicates and repeated at least three times in independent experiments.

\subsection{Colony Formation by Clonogenic Assay}

HEC-1A and Ishikawa cells were seeded into 6-well plates at a density of 5000 cells/well and incubated in a normal or high glucose, drug-free medium for $24 \mathrm{~h}$. Afterwards, cells were treated with different concentrations of metformin (0.01 $5.0 \mathrm{mM}$ ) for $7 \mathrm{~d}$ with regular medium changes every 2 - $3 \mathrm{~d}$. Untreated cells served as the reference control. Subsequently, cells were stained with $0.5 \%(\mathrm{w} / \mathrm{v})$ $\mathrm{CV}$, washed three times with PBS and air-dried before image acquisition. The colony formation was quantified as \% area with the ImageJ software [24] and the ColonyArea plugin [25]. All experiments were repeated at least three times.

\subsection{Cell Migration by Wound Healing Assay}

Cell migration was assessed by quantifying the \% wound closure in the wound healing assay. The cells were seeded into 6-well plates at a density of 50,000 cells/well in a normal or high glucose, substance-free medium for $24 \mathrm{~h}$. Afterwards, cells were treated with selected concentrations of metformin (0.5 or 5.0 $\mathrm{mM}$ ) for $7 \mathrm{~d}$ with medium changes every 2 - $3 \mathrm{~d}$. After $7 \mathrm{~d}$, the confluent monolayers were wounded using a sterile pipette tip and the medium was replaced by fresh, substance-containing normo- or hyperglycemic medium in order to remove cellular debris. Representative images were taken with an inverse light microscope (Leica, Munich, Germany) at 40× magnification directly and $24 \mathrm{~h}$ after wounding of the monolayer. The migration area A was measured using the ImageJ software [24] and the \% wound closure was calculated with the following Equation (3):

$$
\left(A_{t=0 \mathrm{~h}}-A_{t=24 \mathrm{~h}}\right) / A_{t=0 \mathrm{~h}} \times 100 \text {, }
$$

where $A_{t=0 \mathrm{~h}}$ and $A_{t=24 \mathrm{~h}}$ are the area of the wound immediately after scratching ( 0 h) and $24 \mathrm{~h}$ later, respectively. Measurements were taken after $24 \mathrm{~h}$ in order to limit the observations to migration rather than cellular proliferation [26]. HEC-1A and Ishikawa cells display doubling times of 27 - $29 \mathrm{~h}$ during routine culture, and thus the effect of proliferation in the wound healing assay was mi- 
nimized. All experiments were repeated at least three times in duplicates.

\subsection{Statistical Analysis}

Quantitative data are presented as mean \pm standard error of the mean (SEM) of at least three independent experiments. SPSS version 24 (IBM, Armonk, NY, USA) was used to perform a generalized estimating equation test or a paired t-test, as appropriate. A $p$ value $\leq 0.05$ was considered statistically significant.

\section{Results}

\subsection{Long-Term Metformin Treatment Decreased Endometrial Cancer Cell Viability and Proliferation Rate}

Firstly, the effects of metformin on cellular viability were analyzed after long-term treatment with metformin for $7 \mathrm{~d}$ with the MTT cell viability assay and $\mathrm{IC}_{50}$ and $\mathrm{IC}_{90}$ values were calculated (Figure $1(\mathrm{a})$ and Table 1 ). The $\mathrm{IC}_{50}$ values for Ishikawa cells were $3.7 \mathrm{mM}\left(\mathrm{IC}_{90}: 14.9 \mathrm{mM}\right)$ under normal glucose conditions and $3.0 \mathrm{mM}\left(\mathrm{IC}_{90}: 13.7 \mathrm{mM}\right)$ in a high glucose environment. For HEC-1A cells, an $\mathrm{IC}_{50}$ value of $0.7 \mathrm{mM}\left(\mathrm{IC}_{90}: 6.1 \mathrm{mM}\right)$ was established under normal glucose conditions. No $\mathrm{IC}_{50}$ and $\mathrm{IC}_{90}$ values could be calculated for HEC-1A in high glucose medium due to repeated overgrowth of the substrate surface by the cells. At a concentration of $\leq 0.1 \mathrm{mM}$, cellular viability for both cell lines was $\geq 80 \%$ compared to an untreated control, irrespective of glucose levels in the media. Cellular viability dropped to $\leq 10 \%$ at concentrations higher than 5.0 (HEC-1A) and $10 \mathrm{mM}$ (Ishikawa) under any tested metabolic condition in a concentration-dependent manner.

Additionally, cellular viability was determined based on ATP levels with the ATP cell viability assay and, again, $\mathrm{IC}_{50}$ and $\mathrm{IC}_{90}$ values were calculated (Figure 1 (b) and Table 1). The $\mathrm{IC}_{50}$ values for Ishikawa cells were $2.1 \mathrm{mM}\left(\mathrm{IC}_{90}: 5.0\right.$ $\mathrm{mM})$ under normal glucose conditions and $18.3 \mathrm{mM}\left(\mathrm{IC}_{90}:>20.0 \mathrm{mM}\right)$ in a high glucose environment. For HEC-1A cells, an $\mathrm{IC}_{50}$ value of $2.0 \mathrm{mM}\left(\mathrm{IC}_{90}: 4.6 \mathrm{mM}\right)$ was established under normal glucose conditions. No exact $\mathrm{IC}_{50}$ and $\mathrm{IC}_{90}$ values could be calculated for HEC-1A in high glucose medium due to the high remaining cellular activity at the greatest tested metformin concentration of 20.0 $\mathrm{mM}$. At a concentration of $\leq 1.0 \mathrm{mM}$, cellular viability for both cell lines was $\geq 80 \%$ compared to an untreated control at normoglycemia, while higher concentrations of $>5.0$ (Ishikawa) and $>10.0 \mathrm{mM}$ (HEC-1A) were necessary to decrease cellular viability below $80 \%$ in a high glucose environment. Cellular viability dropped to $\leq 10 \%$ at concentrations $>5.0 \mathrm{mM}$ for both cell lines in a normoglycemic environment, while concentrations of $10-20 \mathrm{mM}$ were necessary in the presence of hyperglycemic conditions. In general, the detected inhibitory concentrations for metformin were substantially higher in the ATP assay at high glucose levels. Supplementation with E2 alone did not affect cellular viability in the ATP assay (96.6\% - 100.4\%) (Figure S1(a)).

In order to evaluate the effects of metformin and the role of glucose on endometrial cancer proliferation during long-term treatment, the present study 
HEC-1A

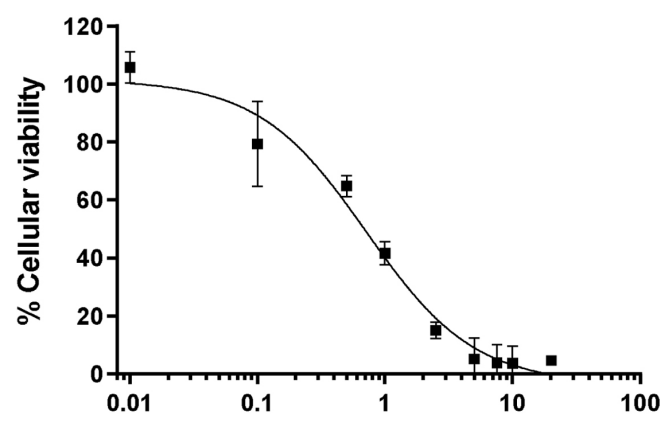

(a)
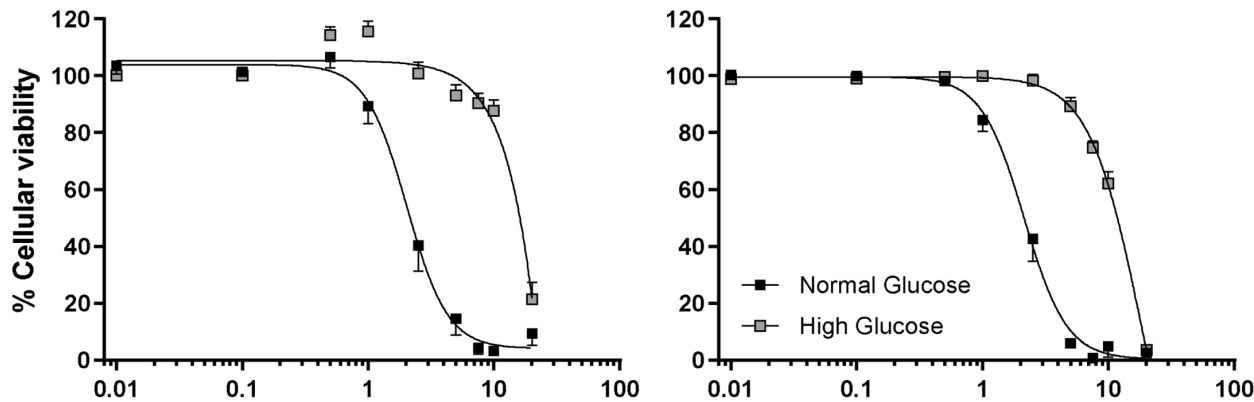

(b)
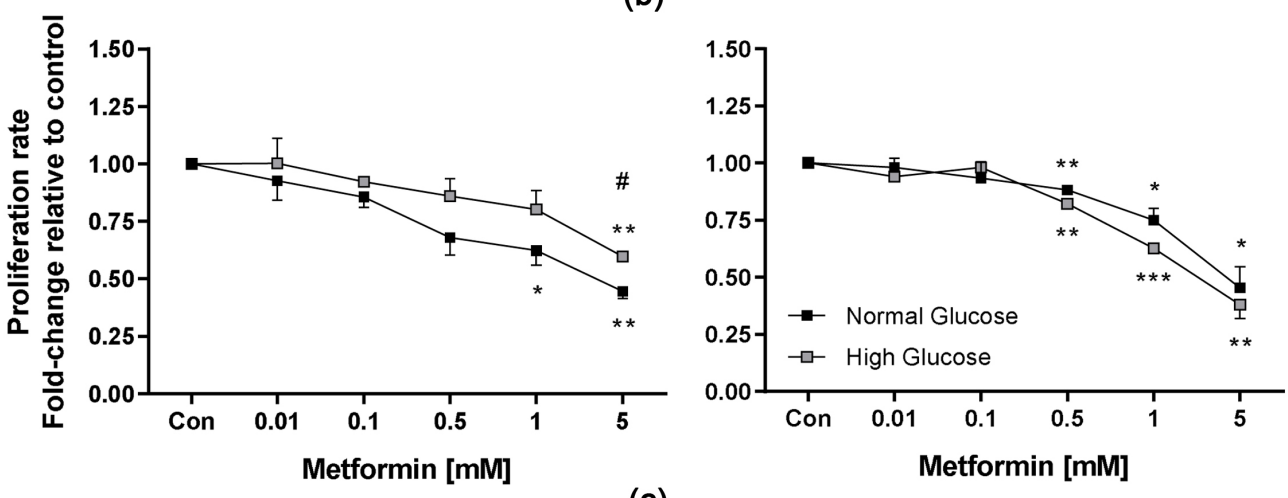

(c)

Figure 1. Effects of metformin on cellular viability and proliferation of EC cells as assessed by the MTT or ATP assay and the crystal violet (CV) assay. HEC-1A and Ishikawa cells were treated with 0.01 - 20 mM (MTT, (a); ATP, (b)) or 0.01 - $5.0 \mathrm{mM} \mathrm{(CV,} \mathrm{(c))} \mathrm{metformin} \mathrm{in} \mathrm{a} \mathrm{normoglycemic} \mathrm{(} \mathbf{-} ; 5.5$ $\mathrm{mM}$ glucose) or hyperglycemic ( ; $17.5 \mathrm{mM}$ glucose) environment for $7 \mathrm{~d}$. Untreated cells served as reference controls in the assays. Results are presented as mean \pm SEM from at least three independent experiments; (c) ${ }^{\star} p \leq 0.05,{ }^{* *} p \leq 0.01,{ }^{* *} p \leq 0.001$ (metformin vs. control); ${ }^{*} p \leq 0.05$ (normoglycemia vs. hyperglycemia); $\mathrm{n} \geq 3$.

examined changes in growth after treatment with low and moderate concentrations of metformin after $7 \mathrm{~d}$ (Figure $1(\mathrm{c})$ ). Independent of the glucose concentration in the medium, the lowest metformin concentrations $(0.01$ and $0.1 \mathrm{mM})$ did not show any effect on the growth potential of HEC-1A or Ishikawa cells compared to untreated reference cells. Nevertheless, metformin concentrations of $0.5,1.0$ and $5.0 \mathrm{mM}$ led to a decrease in proliferation of HEC-1A cells at normal glucose levels by $32 \%(p=0.051), 38 \%(p=0.026)$ and $55 \%(p=0.003)$, 
Table 1. Established $\mathrm{IC}_{50}$ and $\mathrm{IC}_{90}$ values from MTT and ATP cell viability assays after treatment of HEC-1A and Ishikawa cells with metformin for $7 \mathrm{~d}$. Data presented as means with $[95 \%$ confidence interval (CI)].

\begin{tabular}{|c|c|c|c|c|c|c|c|c|}
\hline & \multicolumn{4}{|c|}{ MTT assay } & \multicolumn{4}{|c|}{ ATP assay } \\
\hline & \multicolumn{2}{|c|}{$\begin{array}{c}\mathrm{IC}_{50}[\mathrm{mM}] \\
{[95 \% \mathrm{CI}]}\end{array}$} & \multicolumn{2}{|c|}{$\begin{array}{c}\mathrm{IC}_{90}[\mathrm{mM}] \\
{[95 \% \mathrm{CI}]}\end{array}$} & \multicolumn{2}{|c|}{$\begin{array}{c}\mathrm{IC}_{50}[\mathrm{mM}] \\
{[95 \% \mathrm{CI}]}\end{array}$} & \multicolumn{2}{|c|}{$\begin{array}{c}\mathrm{IC}_{90}[\mathrm{mM}] \\
{[95 \% \mathrm{CI}]}\end{array}$} \\
\hline & NG & HG & NG & HG & NG & HG & NG & HG \\
\hline HEC-1A & $\begin{array}{c}0.7 \\
{[0.4-1.2]}\end{array}$ & - & $\begin{array}{c}6.1 \\
{[3.5-10.2]}\end{array}$ & - & $\begin{array}{c}2.0 \\
{[1.7-2.4]}\end{array}$ & $>10.0$ & $\begin{array}{c}4.6 \\
{[3.9-5.4]}\end{array}$ & $>20.0$ \\
\hline Ishikawa & $\begin{array}{c}3.7 \\
{[2.1-6.5]}\end{array}$ & $\begin{array}{c}3.0 \\
{[2.0-4.6]}\end{array}$ & $\begin{array}{c}14.9 \\
{[9.1-23.7]}\end{array}$ & $\begin{array}{c}13.7 \\
{[9.4-19.8]}\end{array}$ & $\begin{array}{c}2.1 \\
{[1.9-2.4]}\end{array}$ & $\begin{array}{c}18.3 \\
{[9.5-35.2]}\end{array}$ & $\begin{array}{c}5.0 \\
{[4.4-5.7]}\end{array}$ & $>20.0$ \\
\hline
\end{tabular}

respectively. In Ishikawa cells, proliferation rates significantly dropped by $12 \%$ $(p=0.005), 25 \%(p=0.042)$ and $55 \%(p=0.027)$ compared to the control group, when cultured in a normoglycemic environment. However, in the presence of high glucose levels, only the highest metformin concentration (5.0 mM) was able to significantly decrease the proliferation rate of HEC-1A cells $(40 \%$; $p=0.004)$, equal to a $15 \%$ significantly lower effect $(p=0.047)$ compared to results at the same metformin concentration under normoglycemic conditions. Yet, this resistance to metformin was not observed in Ishikawa cells at high glucose concentrations, where even $0.5,1.0$ and $5.0 \mathrm{mM}$ metformin decreased the proliferation rate of cells significantly by $18 \%(p=0.004), 37 \%(p<0.001)$ and $62 \%(p=0.009)$. Therefore, Ishikawa cells did not show a glucose-dependent resistance in response to metformin treatment. Supplementation with E2 alone did not increase proliferation of HEC-1A cells (proliferation rate of 95.0 (NG) and 97.2\% (HG)) (Figure S1(b)). However, pro-proliferative effects of estrogen supplementation were observed in Ishikawa cells under normo- $(121.3 \%, p=0.026)$ and particularly hyperglycemic conditions $(138.1 \%, p=0.015)$ compared to untreated control cells as well as cells treated with $0.1 \%(\mathrm{v} / \mathrm{v})$ ethanol as a vehicle $(p=0.015(\mathrm{NG})$ and $p=0.018(\mathrm{HG})$ ).

\subsection{Inhibition of Endometrial Cancer Colony Formation by Metformin Treatment}

Considering the excellent indication of long-term tumor cell survival of the colony formation assay in vitro, the effects of metformin on clonogenicity of HEC-1A and Ishikawa cells were assessed when exposed in an environment with normal or high glucose levels (Figure 2). Metformin treatment caused concentration-dependent effects on the colony formation of EC cells and decreased the number and size of the colonies. In HEC-1A cells, $0.5 \mathrm{mM}$ metformin reduced the colony formation by $44 \%$ under normoglycemic conditions $(p=0.021)$ compared to untreated reference cells, but only by $29 \%$ under hyperglycemic conditions $(p=0.041)$, followed by a further reduction with increasing metformin concentrations. Treatment at 1.0 and $5.0 \mathrm{mM}$ metformin inhibited clonogenicity by $59 \%(p=0.0096)$ and $80 \%(p=0.004)$ at $5.5 \mathrm{mM}$ glucose as well as $42 \%$ 
HEC-1A

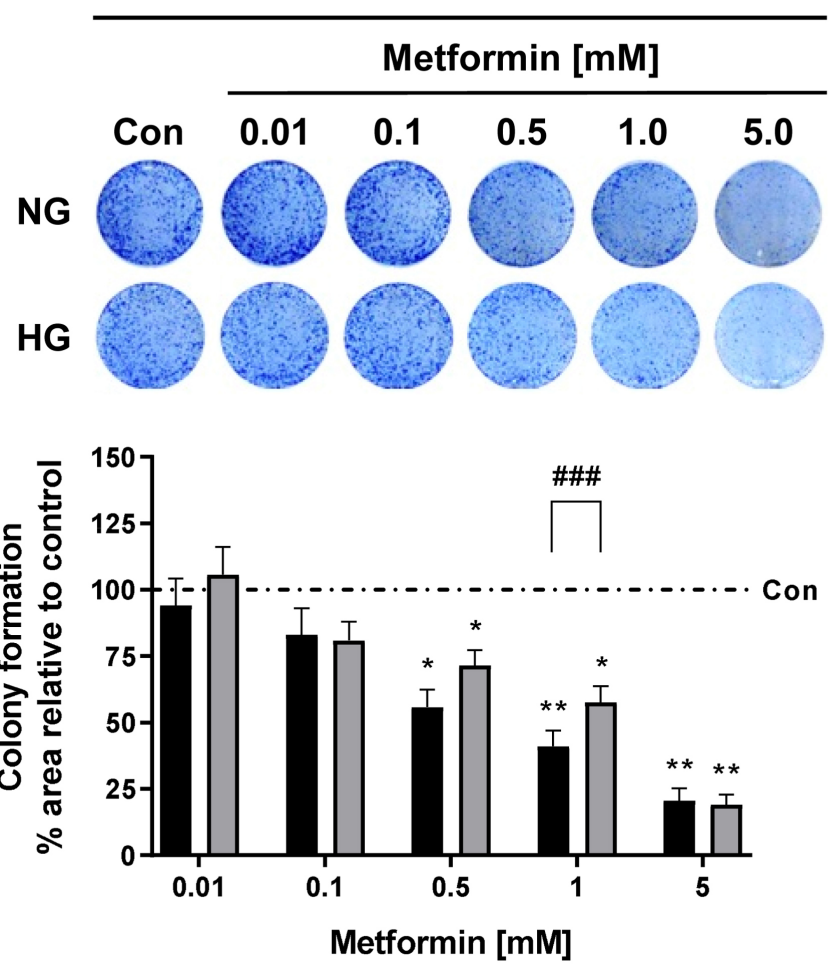

Ishikawa

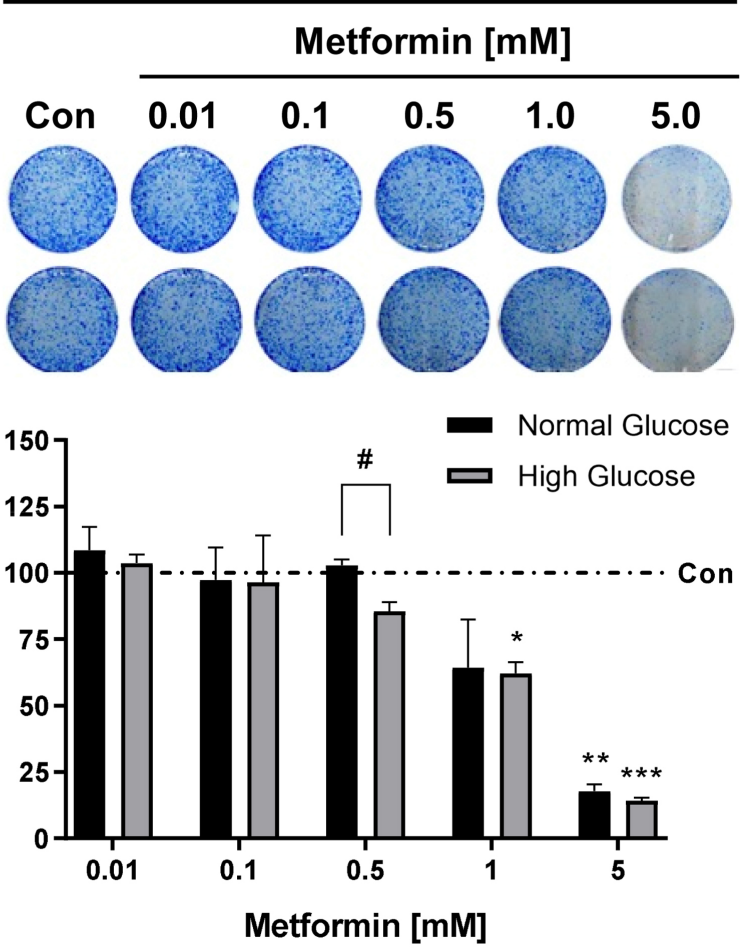

Figure 2. Effects of metformin on clonogenicity of EC cells as detected in the colony formation assay. HEC-1A and Ishikawa cells were treated with $0.01-5.0 \mathrm{mM}$ metformin in a normoglycemic $(-; 5.5 \mathrm{mM}$ glucose) or hyperglycemic ( $" ; 17.5 \mathrm{mM}$ glucose) environment for $7 \mathrm{~d}$. Untreated cells served as a reference control in the assay. The colony formation was quantified as $\%$ area with the ImageJ software and the ColonyArea plugin. Data are presented as mean \pm SEM from at least three independent experiments; ${ }^{\star} p \leq$ $0.05,{ }^{* *} p \leq 0.01,{ }^{* * *} p \leq 0.001$ (metformin vs. control); ${ }^{\#} p \leq 0.05,{ }^{\# \# \#} p \leq 0.001$ (normoglycemia vs. hyperglycemia); $\mathrm{n} \geq 3$.

$(p=0.021)$ and $81 \%(p=0.002)$ at $17.0 \mathrm{mM}$ glucose, respectively. Additionally, the colony formation remained significantly higher (17\% difference) at $1.0 \mathrm{mM}$ metformin when cultured under high glucose conditions compared to normoglycemia $(p<0.001)$. A similar glucose-mediated protecting effect was also observed at $0.5 \mathrm{mM}$ metformin, but the $15 \%$ difference in colony formation was not significant. In Ishikawa cells, however, substantial decreases in colony formation under normo- and hyperglycemic conditions were only observed at 1.0 $\mathrm{mM}(36 \%$ and $38 \%, p=0.012)$ and $5.0 \mathrm{mM}$ metformin $(86 \%, p=0.001$ and $82 \%$, $p<0.001)$, respectively. A significant difference in the proliferation rate at different glucose concentrations was observed at $0.5 \mathrm{mM}$ metformin $(p=0.046)$ also in Ishikawa cells. E2 supplementation alone did not generate significant changes in clonogenicity of HEC-1A (104.3 (NG) and 102.8\% (HG)) and Ishikawa cells (102.7 (NG) and 100.1\% (HG)) (Figure S1(c)).

\subsection{Metformin Long-Term Treatment Reduced Endometrial Cancer Motility}

Considering the doubling time of HEC-1A and Ishikawa cells of $27-29 \mathrm{~h}$, motility of EC cells after long-term metformin treatment was evaluated by a wound healing assay after $24 \mathrm{~h}$ to minimize the influence of proliferation on the out 


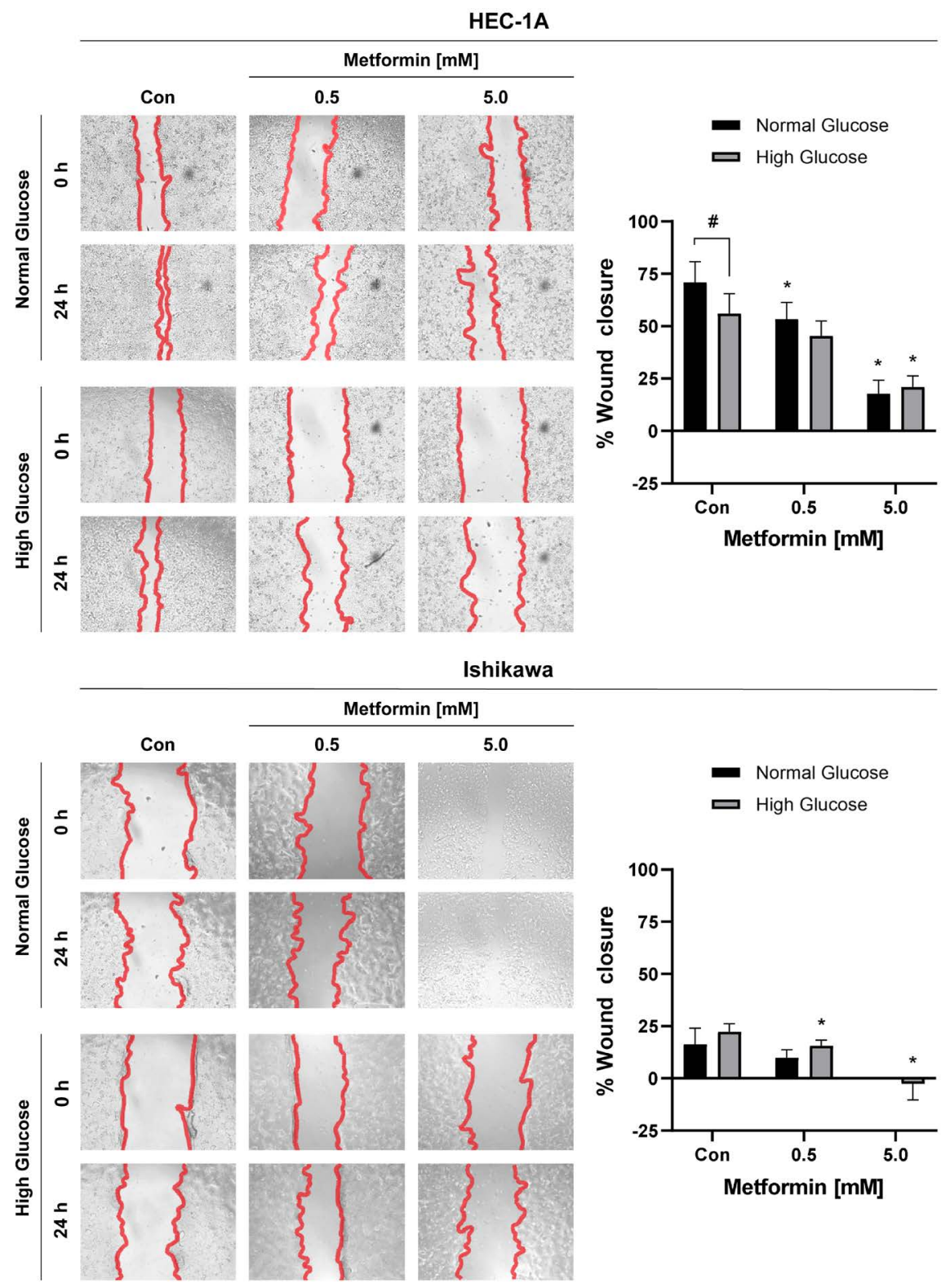

Figure 3. Effects of metformin on migration of EC cells as observed in the wound healing assay. HEC-1A and Ishikawa cells were treated with 0.5 and $5.0 \mathrm{mM}$ metformin in a normoglycemic ( $\backsim ; 5.5 \mathrm{mM}$ glucose) or hyperglycemic ( $-17.5 \mathrm{mM}$ glucose) environment for $7 \mathrm{~d}$. Afterwards, wounds were created by scratching the cell monolayer and the migration area was measured with the help of ImageJ software after $24 \mathrm{~h}$. The migration area A was measured using the ImageJ software and \% wound closure was calculated with the following formula: $\left(A_{t=0 \mathrm{~h}}-A_{t=24 \mathrm{~h}}\right) / A_{t=0 \mathrm{~h}} \times 100 \%$. Untreated cells served as a reference control in the assay. Results are presented as mean \pm SEM from at least three independent experiments; ${ }^{\star} p \leq 0.05$ (metformin vs. control); ${ }^{*} p \leq 0.05$ (normoglycemia vs. hyperglycemia); $\mathrm{n} \geq 3$.

come of the assay (Figure 3). At $24 \mathrm{~h}$ after scratching, untreated HEC-1A controlcells covered the scratch up to $71 \%$ and $56 \%$ at normal and high glucose levels, respectively, while Ishikawa control cells migrated into the scratch wound by $16 \%$ and $22 \%$. Metformin treatment at $0.5 \mathrm{mM}$ significantly reduced the migra- 
tion ability of HEC-1A cells by $18 \%(p=0.031)$ in a normoglycemic environment. However, in a high glucose environment, the migration was reduced by only $11 \%$. Under these conditions, Ishikawa cells showed a minor reduction of motility by only $6 \%-7 \%$ with $0.5 \mathrm{mM}$ metformin at both glucose concentrations, which was significant only under high glucose conditions $(p=0.025)$. The highest effect of metformin was detected at $5.0 \mathrm{mM}$ metformin, where the treatment significantly inhibited the motility of HEC-1A cells by $53 \%(p=0.004)$ and $35 \%(p=0.009)$ at 5.5 and $17.0 \mathrm{mM}$ glucose, respectively. In Ishikawa cells, a drop of the motility rate by $25 \%(p=0.019)$ was observed at high glucose levels with $5.0 \mathrm{mM}$ metformin, resulting in a complete inhibition of cellular motility. The effect of metformin at $5.0 \mathrm{mM}$ on the motility of Ishikawa cells could not be evaluated under normoglycemic conditions due to the fact that cells were not able to build up the required monolayer over a period of $7 \mathrm{~d}$. Nevertheless, this finding highlights the inhibitory effect of high metformin concentrations on the migration capacity of Ishikawa cells at physiological glucose levels. Additionally, it should be noted that a significantly decreased wound closure was observed between untreated control groups under different glucose conditions in the HEC-1A cell line $(p=0.043)$, indicating an inhibiting effect of high glucose levels on motility.

\section{Discussion}

Over the last years, metformin has been suggested as a promising drug for both cancer prevention and treatment with a considerably increased number of experimental and epidemiologic studies [10] [11] [12] [13] [14]. However, despite the fact that an overall $27 \%$ reduction of the risk for developing any type of cancer in metformin-treated patients with type II diabetes has been observed in a meta-analysis of 18 observational studies [27], the drug has not been established as an anti-cancer drug so far, most likely due to methodological weaknesses and insufficient data of currently available studies.

We would like to point out that the anti-proliferative, pro-apoptotic and motility-suppressing effects of metformin on EC described in the literature were analyzed using a short-term exposure of metformin $(24-72 \mathrm{~h})$ at supra-pharmacological concentrations (up to $100 \mathrm{mM}$ ). Moreover, many of these studies were performed in the absence of $\beta$-estradiol, a known risk factor in endometrial proliferative disorders [18] [19] [28]. The hormone displayed pro-proliferative effects in the Ishikawa pre-menopausal cell model in the current study, whereas the HEC-1A post-menopausal cells remained unaffected, which can be explained by a reduced expression of estrogen receptor $\alpha(E R \alpha)$, and thus a lower E2 sensitivity in this cell line [29] [30], underlining the cellular differences in the applied cancer models. Our group previously reported that a low concentration of 0.1 $\mathrm{mM}$ metformin was not able to decrease the proliferation potential of the Ishikawa EC cell line after short-term treatment of $72 \mathrm{~h}$ in vitro, while concentrations of 1.0 - $5.0 \mathrm{mM}$ metformin affected the proliferation rate [21]. However, 
metformin at a concentration of $0.1 \mathrm{mM}$ was able to inhibit the migration ability of EC cells in a normoglycemic environment during short-term treatment and also reduced insulin-induced enhanced motility under hyperglycemic conditions. Also, metformin showed a greater effect on EC cells in the presence of physiological glucose levels [21]. These results encouraged us to examine the direct anti-tumor effects of low and moderate concentrations of metformin on two different types of EC cells in a long-term setting of $7 \mathrm{~d}$ under the addition of E2, a common risk factor for the development of EC, which, to the best of our knowledge, has never been done before in vitro.

The present study used different glucose concentrations in order to mimic the physiological setting associated with EC development and showed that longterm treatment with 0.01 and $0.1 \mathrm{mM}$ metformin did not have any effects on EC proliferation, growth and motility in vitro, independent of glucose levels in the culture medium. The effects of unphysiologically high concentrations of metformin $(0.5-5.0 \mathrm{mM})$ - still considered as low or moderate concentrations for in vitro experiments-were also evaluated in the present study. Results of the MTT and ATP cell viability assays revealed that metformin concentrations $\geq 1.0$ (NG) and $5.0 \mathrm{mM}$ (HG) led to a decreased cellular viability of both EC cell lines. Thus, it cannot be excluded that changes in proliferation rates are at least to some extent related to a loss of cellular viability. Furthermore, the results of the present study have shown that HEC-1A and Ishikawa cells react differently to metformin, as i.e. HEC-1A cells were more sensitive to the biguanide drug in terms of cellular viability. In addition, HEC-1A cells in particular showed a high proliferation rate and cellular viability at high glucose levels (Figure 1), which may explains their more aggressive behavior, especially in a high glucose environment. According to our results, the two cell lines responded very differently to metformin within the distinct metabolic conditions. As mentioned above, it is important to take into consideration that the HEC-1A and Ishikawa cell lines differ in their gene expression profile, such as the gene encoding for ER and metabolic enzymes and therefore represent different in vitro models. Ishikawa cells represent a model for estrogen-dependent, pre-menopausal EC expressing various ER to different extents, whereas HEC-1A cells represent a model for postmenopausal EC with lower sensitivity to E2, and are lacking ER $\alpha$ expression. But it was also shown that HEC-1A cells express ER $\beta$ and G protein-coupled estrogen receptor 1 (GPER) and therefore maintain a low estrogen sensitivity [29] [30]. Therefore, resistance to metformin effects exhibited by cells cultured in an environment with $17.0 \mathrm{mM}$ glucose might to some extent be driven by differences in ER expression. Filigheddu et al. detected stimulating effects of E2 on cellular proliferation, migration and growth of HEC-1A cells independent of ER $\alpha$ via a GPER-mediated activation of diacylglycerol kinase $\alpha$ (DGK $\alpha$ ) [31], but these results were not confirmed in our study, as no effects of E2 supplementation on proliferation, clonogenicity or cellular viability of HEC-1A cells were observed. 
Mitsuhashi and colleagues compared metformin concentrations in vivo with in vitro results and the analysis revealed that the concentration of metformin required for growth suppression in vivo was 400 -fold lower than the respective concentration that inhibited cellular growth in vitro $(1.0 \mathrm{mM}$ for Ishikawa and HEC-1B cells after $72 \mathrm{~h}$ ) [28]. This effect may be attributed to the fact that metformin has an additional peripheral effect on the reduction of the hyperglycemia due to its known benefit on insulin-sensitizing of the tissues, leading to a normalization of glucose levels [10] [28]. This hypothesis was supported by our results, as the estrogen-independent HEC-1A cells were resistant to the direct inhibiting effect of metformin on proliferation at very high metformin concentrations of $5.0 \mathrm{mM}$ only in the hyperglycemic environment, while an anti-proliferative effect was already detected at $0.5 \mathrm{mM}$ in a more physiological glucose environment (Figure 1). Additionally, HEC-1A cells overgrew the substrate surface in the high glucose environment, making it impossible to evaluate cellular viability in the MTT assay after $7 \mathrm{~d}$. Similar effects on HEC-1A cells were observed in the colony formation assay as well as the migration analysis, where the direct metformin effects were substantially lower in a hyperglycemic microenvironment (Figure 2 and Figure 3). As this effect was not noted in Ishikawa cells, the more aggressive type II HEC-1A cell line may be fueled more in growth and tumorigenesis by elevated glucose levels. However, further experiments are necessary to confirm these findings and to define the molecular effects involved. Additionally, it has to be noted that both cell lines were cultivated under the influence of deviating serum concentrations, i.e. $5 \%(\mathrm{v} / \mathrm{v})$ for Ishikawa and $10 \%(\mathrm{v} / \mathrm{v})$ for HEC-1A, which might constitutes to the resistance against metformin developed by HEC-1A cells, although the same conditions were used in the respective controls.

Moreover, hyperglycemia is associated with obesity and insulin resistance, leading to hyperinsulinemia that stimulated cellular growth and hyperplasia in different tissues [32] [33] [34]. Tumorigenesis of obesity-associated EC was linked to enhanced cellular glucose uptake and increased metabolism [35], but can also be related to increased proliferation in vitro, as seen in the present study between untreated control cells. Consequently, agents like metformin, that decrease glucose and insulin levels, might be a strategy to prevent EC development and progression, while it shows less effect in type I EC according to our in vitro results. Accumulating evidence from in vitro and in vivo studies suggests that metformin acts as an anti-tumor agent directly and indirectly [10], which was also supported by our findings regarding to the direct effects. Prior studies indicated several indirect effects by metformin, including the systemic reduction of blood glucose and insulin levels, whereas the activation of 5' adenosine monophosphate-activated protein kinase (AMPK) served as an example for direct effects on cancer cells [6] [10] [18] [21] [36] [37]. However, multiple other direct mechanisms have been demonstrated, e.g. an upregulation of markers for cell cycle arrest, apoptosis, and autophagy, the inhibition of cell migration and proliferation, as well as a downregulation of markers associated with cellular senes- 
cence [18] [21] [36] [37].

Although studies evaluating the relationship between metformin and EC incidence revealed conflicting results [38] [39], mainly due to a lack of well-designed and adequately powered randomized controlled trials, the findings of the present in vitro study supports the hypothesis that metformin not only displays indirect effects on cancer metabolism via changes of the metabolic environment, but also direct effects on endometrial cells that may prevent hyperplasia and EC development. This accounts particularly for the aggressive type II cancer, as type II post-menopausal HEC-1A cells proliferated more under hyperglycemic conditions and cells were less sensitive to the direct metformin effects at elevated glucose levels. On the other hand, pre-menopausal Ishikawa cells that reflect the more common and less aggressive type I EC only showed minor differences regarding the direct metformin effects under normo- and hyperglycemic conditions, suggesting that these effects were independent of the glucose state.

\section{Conclusion}

In conclusion, the present study highlighted the importance of the metabolic environment in EC development and progression, and potential actions of metformin as a therapeutic agent in the treatment for EC subtypes. Furthermore, it was shown that metformin acts on endometrial cancer cell lines via direct effects, in addition to its well-known indirect effects, i.e. lowering serum glucose levels. These findings suggest that the drug might be a potential adjuvant agent in EC therapy. However, further studies are required to elucidate the role of metformin in EC prevention and treatment in more detail in order to define the relevance of our data for clinical applications.

\section{Author Contributions}

Conceptualization: A.M.W., A.G.; methodology: A.M.W., C.L., A.G.; software: A.M.W., C.L.; validation: A.M.W., J.J.; formal analysis: A.M.W., J.J., C.L.; investigation: A.M.W., C.L.; resources: A.G., T.S.; data curation: A.M.W., C.L.; writing-original draft preparation: A.M.W., C.L., A.G.; writing-review and editing: C.L., A.M.W., A.G.; visualization: A.M.W., C.L.; supervision: A.G.; project administration: A.M.W., A.G.; funding acquisition: A.G. All authors have read and agreed to the published version of the manuscript.

\section{Funding}

This study was supported by the Department of Gynecologic Endocrinology and Fertility Disorders (University Women's Hospital, Ruprecht-Karls University of Heidelberg, Heidelberg, Germany) and the Deutsche Forschungsgemeinschaft (DFG; grant: GE 1173/2-1 to A.G.). The funding bodies had no role in study design, data collection, analysis and interpretation, writing and the decision to submit the manuscript for publication. 


\section{Conflicts of Interest}

The authors declare no conflicts of interest.

\section{References}

[1] Bray, F., Ferlay, J., Soerjomataram, I., Siegel, R.L., Torre, L.A. and Jemal, A. (2018) Global Cancer Statistics 2018: GLOBOCAN Estimates of Incidence and Mortality Worldwide for 36 Cancers in 185 Countries. CA: A Cancer Journal for Clinicians, 68, 394-424. https://doi.org/10.3322/caac.21492

[2] Garg, K. and Soslow, R.A. (2014) Endometrial Carcinoma in Women Aged 40 Years and Younger. Archives of Pathology \& Laboratory Medicine, 138, 335-342. https://doi.org/10.5858/arpa.2012-0654-RA

[3] Amant, F., Mirza, M.R., Koskas, M. and Creutzberg, C.L. (2018) Cancer of the Corpus Uteri. International Journal of Gynecology \& Obstetrics, 143, 37-50. https://doi.org/10.1002/ijgo.12612

[4] O’Connor, K.A., Ferrell, R.J., Brindle, E., Shofer, J., Holman, D.J., Miller, R.C., et al. (2009) Total and Unopposed Estrogen Exposure across Stages of the Transition to Menopause. Cancer Epidemiology, Biomarkers \& Prevention, 18, 828-836. https://doi.org/10.1158/1055-9965.EPI-08-0996

[5] Clarke, C.L. and Sutherland, R.L. (1990) Progestin Regulation of Cellular Proliferation. Endocrine Reviews, 11, 266-301. https://doi.org/10.1210/edrv-11-2-266

[6] Liu, Z., Qi, S., Zhao, X., Li, M., Ding, S., Lu, J., et al. (2016) Metformin Inhibits $17 \beta$-Estradiol-Induced Epithelial-to-Mesenchymal Transition via $\beta$ Klotho-Related ERK1/2 Signaling and AMPK $\alpha$ Signaling in Endometrial Adenocarcinoma Cells. Oncotarget, 7, 21315-12331. https://doi.org/10.18632/oncotarget.7040

[7] Szablewski, L. (2014) Diabetes Mellitus: Influences on Cancer Risk. Diabetes/Metabolism Research and Reviews, 30, 543-553.

https://doi.org/10.1002/dmrr.2573

[8] Friberg, E., Orsini, N., Mantzoros, C.S. and Wolk, A. (2007) Diabetes Mellitus and Risk of Endometrial Cancer: A Meta-Analysis. Diabetologia, 50, 1365-1374. https://doi.org/10.1007/s00125-007-0681-5

[9] Barone, B.B., Yeh, H.C., Snyder, C.F., Peairs, K.S., Stein, K.B., Derr, R.L., et al. (2008) Long-Term All-Cause Mortality in Cancer Patients with Preexisting Diabetes Mellitus: A Systematic Review and Meta-Analysis. JAMA, 300, 2754-2764. https://doi.org/10.1001/jama.2008.824

[10] Daugan, M., Dufay Wojcicki, A., d'Hayer, B. and Boudy, V. (2016) Metformin: An Anti-Diabetic Drug to Fight Cancer. Pharmacological Research, 113, 675-685. https://doi.org/10.1016/j.phrs.2016.10.006

[11] Dowling, R.J., Niraula, S., Stambolic, V. and Goodwin, P.J. (2012) Metformin in Cancer: Translational Challenges. Journal of Molecular Endocrinology, 48, R31-R43. https://doi.org/10.1530/JME-12-0007

[12] Umene, K., Banno, K., Kisu, I., Yanokura, M., Nogami, Y., Tsuji, K., et al. (2013) New Candidate Therapeutic Agents for Endometrial Cancer: Potential for Clinical Practice. Oncology Reports, 29, 855-860. https://doi.org/10.3892/or.2013.2221

[13] Febbraro, T., Lengyel, E. and Romero, I.L. (2014) Old Drug, New Trick: Repurposing Metformin for Gynecologic Cancers? Gynecologic Oncology, 135, 614-621. https://doi.org/10.1016/j.ygyno.2014.10.011

[14] He, H., Ke, R., Lin, H., Ying, Y., Liu, D. and Luo, Z. (2015) Metformin, an Old Drug, Brings a New Era to Cancer Therapy. The Cancer Journal, 21, 70-74. 
https://doi.org/10.1097/PPO.0000000000000103

[15] Samuel, V.P., Dahiya, R., Singh, Y., Gupta, G., Sah, S.K., Gubbiyappa, S.K., et al. (2019) Metformin: A Salutary Candidate for Colorectal Cancer Treatment in Patients with Diabetes. Journal of Environmental Pathology, Toxicology and Oncolo$g y, 38,133-141$. https://doi.org/10.1615/JEnvironPatholToxicolOncol.2019029388

[16] Abdel-Wahab, A.F., Mahmoud, W. and Al-Harizy, R.M. (2019) Targeting Glucose Metabolism to Suppress Cancer Progression: Prospective of Anti-Glycolytic Cancer Therapy. Pharmacological Research, 150, Article ID: 104511. https://doi.org/10.1016/j.phrs.2019.104511

[17] Coperchini, F., Leporati, P., Rotondi, M. and Chiovato, L. (2015) Expanding the Therapeutic Spectrum of Metformin: From Diabetes to Cancer. Journal of Endocrinological Investigation, 38, 1047-1055.

https://doi.org/10.1007/s40618-015-0370-z

[18] Wallbillich, J.J., Josyula, S., Saini, U., Zingarelli, R.A., Dorayappan, K.D., Riley, M.K., et al. (2017) High Glucose-Mediated STAT3 Activation in Endometrial Cancer Is Inhibited by Metformin: Therapeutic Implications for Endometrial Cancer. PLoS ONE, 12, e0170318. https://doi.org/10.1371/journal.pone.0170318

[19] Wu, B., Li, S., Sheng, L., Zhu, J., Gu, L., Shen, H., et al. (2012) Metformin Inhibits the Development and Metastasis of Ovarian Cancer. Oncology Reports, 28, 903-908. https://doi.org/10.3892/or.2012.1890

[20] Machado Weber, A., Strowitzki, T. and Germeyer, A. (2018) High Glucose Levels Interferes the Endometrial Cancer Cell Response to Metformin Treatment over Time. British Journal of Research, 5, Article No. 44. https://doi.org/10.21767/2394-3718.100044

[21] de Barros Machado, A., Dos Reis, V., Weber, S., Jauckus, J., Brum, I.S., von Eye Corleta, H., et al. (2016) Proliferation and Metastatic Potential of Endometrial Cancer Cells in Response to Metformin Treatment in a High versus Normal Glucose Environment. Oncology Letters, 12, 3626-3632. https://doi.org/10.3892/ol.2016.5041

[22] Shao, R., Li, X., Feng, Y., Lin, J.F. and Billig, H. (2014) Direct Effects of Metformin in the Endometrium: A Hypothetical Mechanism for the Treatment of Women with PCOS and Endometrial Carcinoma. Journal of Experimental \& Clinical Cancer Research, 33, Article No. 41. https://doi.org/10.1186/1756-9966-33-41

[23] Feoktistova, M., Geserick, P. and Leverkus, M. (2016) Crystal Violet Assay for Determining Viability of Cultured Cells. Cold Spring Harbor Protocols, 2016, 343-346. https://doi.org/10.1101/pdb.prot087379

[24] Schneider, C.A., Rasband, W.S. and Eliceiri, K.W. (2012) NIH Image to ImageJ: 25 Years of Image Analysis. Nature Methods, 9, 671-675.

https://doi.org/10.1038/nmeth.2089

[25] Guzmán, C., Bagga, M., Kaur, A., Westermarck, J. and Abankwa, D. (2014) ColonyArea: An ImageJ Plugin to Automatically Quantify Colony Formation in Clonogenic Assays. PLoS ONE, 9, e92444. https://doi.org/10.1371/journal.pone.0092444

[26] Grada, A., Otero-Vinas, M., Prieto-Castrillo, F., Obagi, Z. and Falanga, V. (2017) Research Techniques Made Simple: Analysis of Collective Cell Migration Using the Wound Healing Assay. Journal of Investigative Dermatology, 137, e11-e16. https://doi.org/10.1016/j.jid.2016.11.020

[27] Franciosi, M., Lucisano, G., Lapice, E., Strippoli, G. F., Pellegrini, F. and Nicolucci, A. (2013) Metformin Therapy and Risk of Cancer in Patients with Type 2 Diabetes: Systematic Review. PLoS ONE, 8, e71583. 
https://doi.org/10.1371/journal.pone.0071583

[28] Mitsuhashi, A., Kiyokawa, T., Sato, Y. and Shozu, M. (2014) Effects of Metformin on Endometrial Cancer Cell Growth in Vivo: A Preoperative Prospective Trial. Cancer, 120, 2986-2995. https://doi.org/10.1002/cncr.28853

[29] Qu, W., Zhao, Y., Wang, X., Qi, Y., Zhou, C., Hua, Y. et al. (2019) Culture Characters, Genetic Background, Estrogen/Progesterone Receptor Expression, and Tumorigenic Activities of Frequently Used Sixteen Endometrial Cancer Cell Lines. Clinica Chimica Acta, 489, 225-232. https://doi.org/10.1016/j.cca.2018.08.013

[30] Hevir-Kene, N. and Rižner, T.L. (2015) The Endometrial Cancer Cell Lines Ishikawa and HEC-1A, and the Control Cell Line HIEEC, Differ in Expression of Estrogen Biosynthetic and Metabolic Genes, and in Androstenedione and Estrone-Sulfate Metabolism. Chemico-Biological Interactions, 234, 309-319.

https://doi.org/10.1016/j.cbi.2014.11.015

[31] Filigheddu, N., Sampietro, S., Chianale, F., Porporato, P.E., Gaggianesi, M., Gregnanin, I., et al. (2011) Diacylglycerol Kinase $\alpha$ Mediates 17- $\beta$-Estradiol-Induced Proliferation, Motility, and Anchorage-Independent Growth of Hec-1A Endometrial Cancer Cell Line through the G Protein-Coupled Estrogen Receptor GPR30. Cellular Signalling, 23, 1988-1996. https://doi.org/10.1016/j.cellsig.2011.07.009

[32] Lu, J., Zhang, X., Zhang, R. and Ge, Q. (2015) MicroRNA Heterogeneity in Endometrial Cancer Cell Lines Revealed by Deep Sequencing. Oncology Letters, 10, 3457-3465. https://doi.org/10.3892/ol.2015.3776

[33] Wise, M.R., Jordan, V., Lagas, A., Showell, M., Wong, N., Lensen, S., et al. (2016) Obesity and Endometrial Hyperplasia and Cancer in Premenopausal Women: A Systematic Review. American Journal of Obstetrics \& Gynecology, 214, 689E.1-689E.17. https://doi.org/10.1016/j.ajog.2016.01.175

[34] Ryu, T.Y., Park, J. and Scherer, P.E. (2014) Hyperglycemia as a Risk factor for Cancer Progression. Diabetes \& Metabolism Journal, 38, 330-336. https://doi.org/10.4093/dmj.2014.38.5.330

[35] Berger, N.A. (2014) Obesity and Cancer Pathogenesis. Annals of the New York Academy of Sciences, 1311, 57-76. https://doi.org/10.1111/nyas.12416

[36] Cantrell, L.A., Zhou, C., Mendivil, A., Malloy, K.M., Gehrig, P.A. and Bae-Jump, V.L. (2010) Metformin Is a Potent Inhibitor of Endometrial Cancer Cell Proliferation-Implications for a Novel Treatment Strategy. Gynecologic Oncology, 116, 92-98. https://doi.org/10.1016/j.ygyno.2009.09.024

[37] Takahashi, A., Kimura, F., Yamanaka, A., Takebayashi, A., Kita, N., Takahashi, K., et al. (2014) Metformin Impairs Growth of Endometrial Cancer Cells via Cell Cycle Arrest and Concomitant Autophagy and Apoptosis. Cancer Cell International, 14, Article No. 53. https://doi.org/10.1186/1475-2867-14-53

[38] Luo, J., Beresford, S., Chen, C., Chlebowski, R., Garcia, L., Kuller, L., et al. (2014) Association between Diabetes, Diabetes Treatment and Risk of Developing Endometrial Cancer. British Journal of Cancer, 111, 1432-1439. https://doi.org/10.1038/bjc.2014.407

[39] Clement, N.S., Oliver, T.R., Shiwani, H., Sanner, J.R., Mulvaney, C.A. and Atiomo, W. (2017) Metformin for Endometrial Hyperplasia. Cochrane Database of Systematic Reviews, No, 10, Article No. CD012214.

https://doi.org/10.1002/14651858.CD012214.pub2 


\section{Supplementary Information}
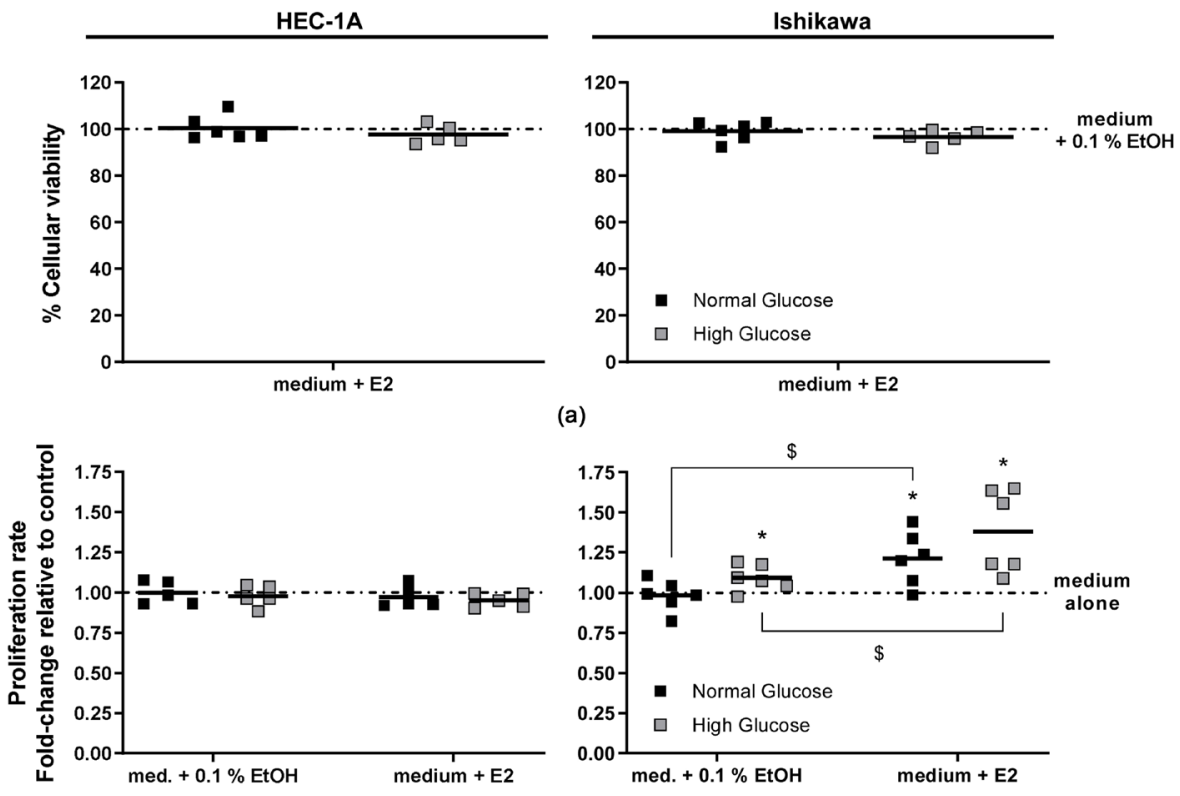

(b)
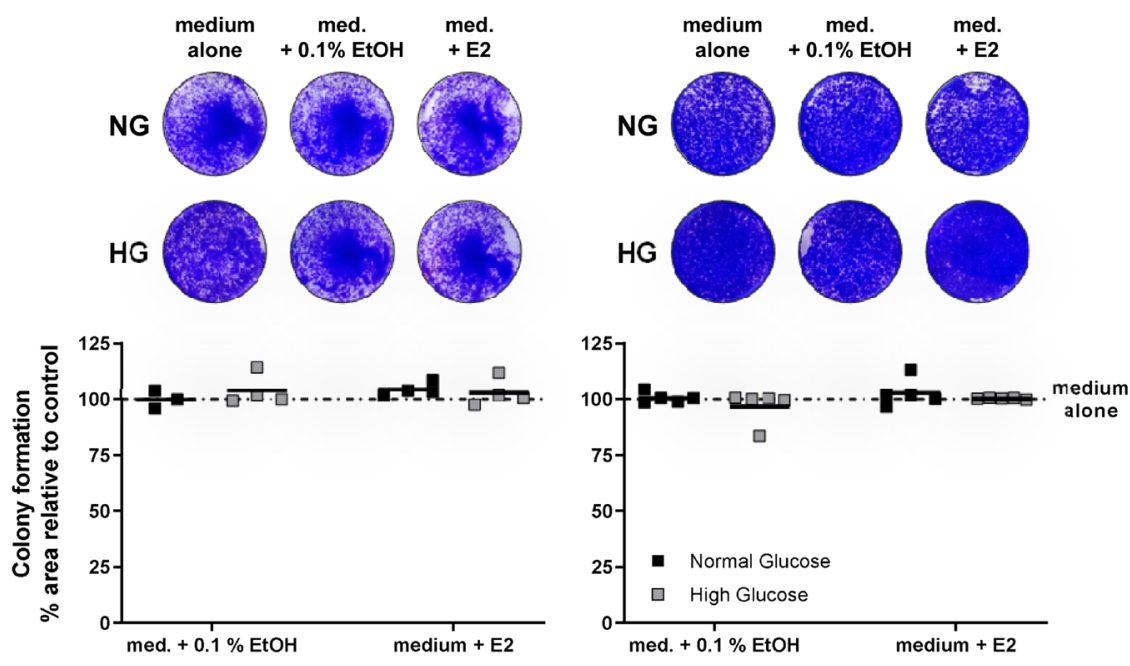

(c)

Figure S1. Effects of E2 supplementation at normal or high glucose levels in different assays. A concentration of $10 \mathrm{nM}$ E2 in medium was freshly prepared directly before use by dilution (1:1000) of a $10 \mu \mathrm{M} \mathrm{E2}$ stock solution in ethanol (final solvent concentration: $0.1 \% \mathrm{EtOH}(\mathrm{v} / \mathrm{v}))$. Cells were treated with E2 in a normoglycemic $(-; 5.5 \mathrm{mM}$ glucose) or hyperglycemic ( $\because 17.5 \mathrm{mM}$ glucose) environment for $7 \mathrm{~d}$ with renewed treatments every $2-3 \mathrm{~d}$. (a) E2 supplementation did not affect cellular viability of HEC-1A (NG: 100.4\%; HG: 97.7\%) and Ishikawa cells (NG: 99.2\%; HG: 96.6\%) in the ATP assay when compared to solvent-treated control cells $(0.1 \%(\mathrm{v} / \mathrm{v}) \mathrm{EtOH})$. (b) Proliferation rate, as assessed by the crystal violet (CV) assay, was not affected in HEC-1A cells (post-menopausal model; NG: 95.0\%; HG: 97.2\%). However, proliferation in Ishikawa (pre-menopausal model) was substantially increased after supplementation with $\mathrm{E} 2$ under normo- $(121.3 \%, p=0.026)$ and hyperglycemic conditions $(138.1 \%, p$ $=0.015)$ in comparison with cells cultivated in medium only or medium with $0.1 \%(\mathrm{v} / \mathrm{v}) \mathrm{EtOH}(p=0.016(\mathrm{NG}) ; p=0.018(\mathrm{HG}))$. Under hyperglycemic conditions, proliferation was also elevated after the addition of $0.1 \%(\mathrm{v} / \mathrm{v}) \mathrm{EtOH}(109.1 \%, p=0.04)$ compared to untreated reference cells, whereas no solvent effects were observed at normal glucose levels (98.2\%). (C) Effects of E2 on clonogenicity, as evaluated by the colony formation assay, were not observed in HEC-1A (NG: 104.3\%; HG: 102.8\%) and Ishikawa cells (NG: 100\%; HG: 100\%) when compared to untreated control cells. The presence of $0.1 \%$ (v/v) EtOH did not affect clonogenicity as well (NG: 102.7\%; HG: 100.1\%). Results are presented as means from at least three independent experiments; ${ }^{*} p \leq 0.05$ (E2 vs. control); ${ }^{\$} p \leq 0.05$ (E2 vs. $0.1 \%$ (v/v) EtOH); $\mathrm{n} \geq 3$. 